\title{
Opening Up the Unfamiliar and Enabling New Pathways for Movement and Becoming: Through, In, and Beyond Attachment
}

\author{
Donna Carlyle, Ian Robson, and Monique Lhussier
}

\begin{abstract}
Donna Carlyle is a doctoral researcher, psychotherapist, and former infant and early years mental health specialist in the NHS, UK. She teaches in the childhood and early years studies program at Northumbria University, Newcastle upon Tyne, UK. Her interests include infant and children's mental health and childhood flourishing. Her doctoral study is an ethnographic exploration of schoolchildren's experiences with and narratives about their interactions with their classroom canine and uses Deleuzoguattarian philosophy to consider affect and kinaesthetic empathy in human-animal interactions (HAI). Her interest in HAI integrates her therapeutic training with a public health perspective. In addition to employing the use of visual-material methods in her research, she considers children's literature, picture books, and fairy tales to be key in supporting children's voices and their social and emotional well-being.

Email: donna.carlyle@northumbria.ac.uk
\end{abstract}

Dr. Ian Robson is a senior lecturer in the department of social work, education, and community well-being in the faculty of health and life sciences at Northumbria University, Newcastle upon Tyne, UK. His teaching and research interests address and are at the intersection of visual art and children and organizational practice, and has a particular focus on visual-material research methods. He is the chair of Newcastle upon Tyne's 1001 Critical Days Think Tank, part of the UK cross-party initiative for the well-being of children from point of conception to age two. He is an artist, leadership coach, and adoptive parent.

Email: ian4.robson@northumbria.ac.uk

Monique Lhussier is an associate professor in public health and well-being at Northumbria University, with particular interests in the welfare and well-being of marginalized groups. She has expertise in a breadth of research approaches, from the conceptualization and deconstruction of pre-existing ubiquitous categories and the development of complexity-consistent and whole systems approaches to study, to the pragmatic evaluation of public health interventions. In particular, her research has used Deleuzoguattarian insights to deconstruct quality of life as a concept that is concomitantly conceptualized and experienced, and has included the use of a Disney feature as a metaphor to critically explore and challenge pervasive cultural understandings of, and attitudes to, quality of life in imperfect conditions.

Email: monique.Ihussier@northumbria.ac.uk

"You see Wendy, when the first baby laughed for the first time, its laugh broke into a thousand pieces, and they all went skipping about, and that was the beginning of fairies"-J.M. Barrie, Peter Pan

\section{A sprinkling of fairy dust to lines of flight}

Fairy tales have afforded children the many places (and spaces) in which to work and rework the pains of growing up and entering into what can be a frightening new world of feelings, affects, and adulthood. It is suggested by Bruno Bettelheim that myths and fairy tales were created to give poignant expression to initiation rites or other rites de passage (Bettelheim, 1975/1991). The stories are not always sunny or optimistic and can take children to the darkest of places: terrifying forests, scary monsters, and aggressive encounters. Yet these places can be the crucial differentiating factors between fairy tales and other children's stories (which often are fictional or educational). Fairy tales are fantastical events that transport both children and adults into a realm of make-believe that encompasses past, present, and future: a disruption akin to the often strange and unfamiliar trope of the fairy tale itself. The use of children's stories as a potent medium that can enable a new perspective on childhood experiences has been explored by Marek Tesar in his dissection of "timing childhoods" (Tesar, 2016). Marilyn Fleer and Marie Hammer (2013) also highlight the importance of fairy tales in the development of affective imagination in children through playful re-enactments to support emotional regulation (Fleer \& Hammer, 2013). In addition, Monique Lhussier (2009) provides an enthralling illustration of the use of metaphor through her depiction of Pinocchio and its juxtaposition with the vagrancies of quality of life in long-term conditions (Lhussier, 2009). She highlights that metaphor and creative, visual thinking help us de-construct (attachment) theory and develop nomadic and rhizomatic thinking, which opens up new pathways for alternative discourse(s). As Bettelheim asserts, the 
The philosophy of Deleuze and Guattari opens up vast potential to disrupt and explore some of the confines of attachment theory when considering the development of enchantment, wishful, and magical thinking in childhood. Through connection with the use of the fairy tale, we seek to illuminate and illustrate the lines of flight, which activate resistance against the universalism of attachment theory and linear process of child development. In using the classic tale of Peter Pan as metaphor, and by applying Deleuzian philosophy and mythology, we aim to expand current thinking about the nature of childhood. By translating text into visual meaning, thus creating a lens with which to view an alternative pathway for child development, relationships as a contemporary adjunct to attachment theory is materialized to produce an affective picture of the non-linear dimension and process of development in children. This sensory aspects of "becoming," which challenges a reductionist view of relationships. In doing so, this allows a state change that enables professionals and scholars to see differently.

Key words: Contemporary attachment theory; fairy tales; child development; spatiality; rhythm; lines of flight; visual portraiture the complexity of the spatiotemporality of affective genre illuminates the embodied and

enchantment of the fairy tale is encapsulated in mythical heroes (Bettelheim, 1975/1991). One such hero is Peter Pan, the forever child who highlights the disruptive aspect of the fairy tale in the sense that he is aware of the past, present, and future (resisting adolescence and adulthood) in a tale where fear and fantasy collide. His story is offered in Western cultures as an example of a boy resisting the transition into adulthood. By reappraising the story of Peter Pan from a Deleuzoguattarian stance, a position of poststructural critical thinking, we can consider the alternative pathways of child development in a similar vein to Bettelheim:

Mythical heroes offer excellent images [our emphasis] for the development of the superego, but the demands they embody are so rigorous as to discourage the child in his fledgling strivings to achieve personality integration. ... the central figure of the fairy-tale lives happily ever after on earth, right among the rest of us. Some fairy-tales conclude with the information that if perchance he has not died, the hero may still be alive. Thus, a happy though ordinary existence is projected by fairy-tales as the outcome of the trials and tribulations involved in the normal growing-up process. (1991, p. 39)

Marina Warner (1995) also describes the genre of the fairy tale as having an important focus on family at the heart of the story (Warner, 1995). She endorses the wonder and enchantment they provide: "pleasure in the fantastic, curiosity about the real” (1995, p. XVI), as Gilles Deleuze and Félix Guattari might suggest, referencing the virtual and actual worlds in which we mingle and meander. It seems inevitable that we should speculate about how fairy tales can assist children in their emotional trails and disruptions: voyages that need to be navigated in order for the destination to be reached. This is what the fairy tale achieves: strife, turmoil, conflict, and ultimately triumph over adversity. They are powerful vehicles, transforming experience and offering positive benefits to emotional well-being (Walker, 2010).

Dylan Dyer argues for "awe, enchantment and a sense of wonder" (2007, p. 391) to be reclaimed by educationalists in order to increase the flow of learning, motivation, and inspiration of scholars. Furthermore, fairy tales have the propensity to enable an opening-up and expansion of attachment theory (how humans and non-humans connect socially and interact with one another), thereby creating lines of flight (new thought processes) and activating alternative pathways through which professionals can understand sensory and embodied elements of child development. For Deleuze, these fairy tales are maps, an intersecting of routes, a découpe or cut-out of space and time, offering different pathways for thinking through childhood experiences and encounters (see Figure 1): 
Every map is a redistribution of impasses and breakthroughs, of thresholds and enclosures .... there is not only a reversal of direction, but also a difference in nature: the unconscious no longer deals with persons or objects, but with trajectories and becomings; it is no longer an unconscious of commemoration but one of mobilization, an unconscious whose objects take flight rather than remaining buried in the ground. (1998, p. 63)

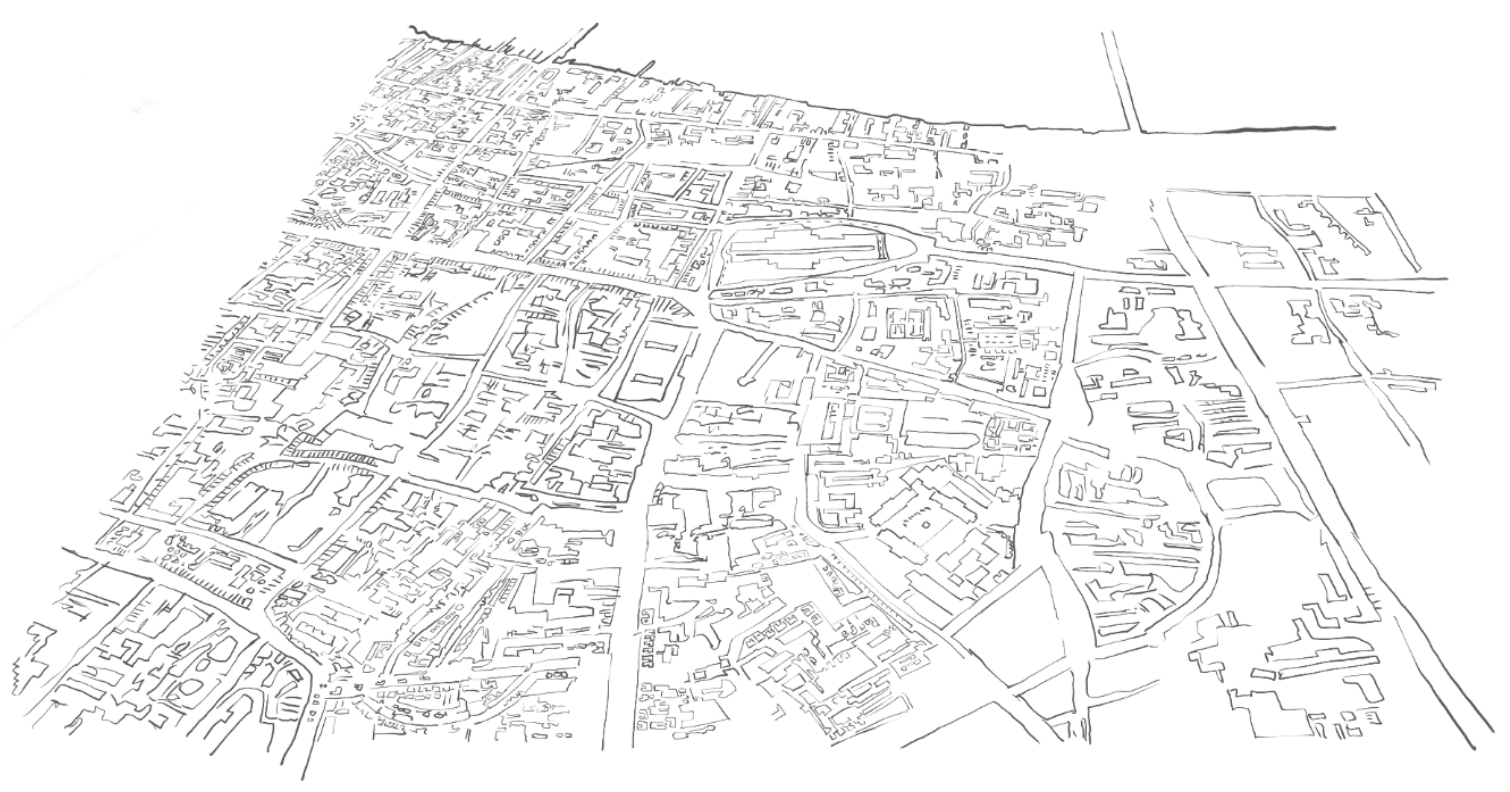

Figure 1. London map.

In becoming enchanted, the trajectory of becoming is through the progression from a striated to smooth space. The real (actual) space invokes a voyage from striated movement to one of smooth movement into the imaginary (virtual) essence of becoming, which we attempt to animate here.

\section{Attachment, affect (agency), and attunement}

John Bowlby provided an evolutionary basis for the making (and breaking) of "affectionate bonds" in his seminal work on how an infant maintains close proximity to their caregiver (usually the mother) for survival (Bowlby, 1979) 1988/1992). This close proximity becomes the "secure base" from which the infant can safely explore the world. It is a base for safe retreat when they are unsure or afraid, a place they return to for sustenance, comfort, and emotional "refuelling." This safety-seeking strategy, for Bowlby, had an evolutionary, survival basis to it, dovetailing his ideas with Darwin's. In expanding on human development, contemporary attachment theorists particularly highlight the fundamental need for social connection, not just throughout infancy but across the entire life span. Attachment can therefore be viewed as the bond that ties. It ties us first to our main attachment figure and then a hierarchy of attachments ensues. This hierarchy comprises both human and non-human relationships-that is, entanglements with the environment, an idea elucidated insightfully by Sarah Whatmore (Whatmore, 1997) —and the Winnicottian notion of the "outside world" (Winnicott, 1964). What remains an intriguing paradox is that childhood is seen through the lens of an enclosed system (the private nuclear family unit), a system of relating that is confined and territorialized. It is both controlled and regulated, codified and classified, or in Deleuzian 


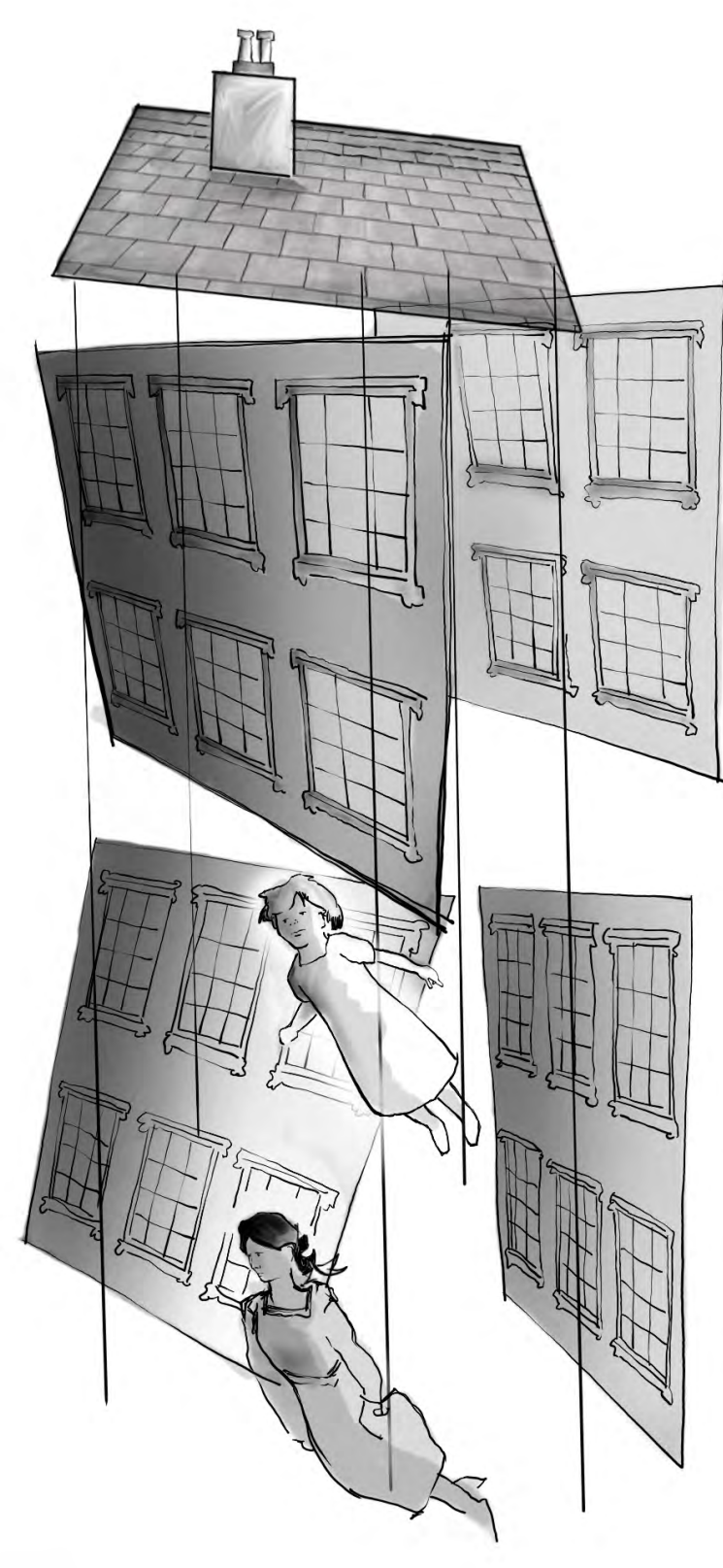

Figure 2. House attached: Restricting "rope," relationships tangled and cut. terms, striated. Therefore, through this article we argue that attachment theory itself requires a deterritoralization to allow for the growth of childhood lines of flight and potentialities (see Figure 2).

There is a spatial element to attaching and attachment theory, a space related to both closeness and distance between interactions that yearn to be "non-representational," not striated as the field of children's geographies asserts (Anderson \& Harrison, 2010; McCormack, 2013). By considering the spatial and temporal nature of relationships we can connect with the idea of continuous movement over time, the sensory elements of experience that Daniel Stern terms "vitality affects" (Stern, 2010). This reinforces the micro-spatiality of interactions, the reciprocal dance, the carefully choreographed matching of each other's affects and bodily rhythms through affect attunement (Stern, 2010). If we consider the rhythm of "events" as postulated by a Deleuzoguattarian perspective (Deleuze \& Guattari, 1988/2013), there can be an unfurling of new understanding, which Stern (2010) asserts in his account of attunement and rhythm in relationships. Robbie Duschinsky, Monica Greco, and Judith Solomon have alluded to the promise of reflecting on the attachment "scene" (Duschinsky et al., 2015b). These events are referred to as affective, rhythmic "events" or "folds" by Deleuze, and could be considered to imply how individual bodies never finish "happening" or "becoming" (Deleuze, 1998) in the world. This requires further amplification through an ontological turn to process, because events can be seen as blocks of spatiotemporal relations and happenings (Deleuze \& Guattari, 1988/2013). This means they are not reduced to codification or striation. They encompass affective elements of gestures and movements but are nonrepresentational and are not predicates. Movement possesses a rhythm, a life, an energy, a vitality. Restricting and confining movements limits our progression, calling for a non-linear and nonbinary distinction.

As Peter Kraftl cautions, the uses of attachment theory are propagating and probing specific modes of ordering social spaces (Kraftl, 2013). This is a noteworthy point, and one that must be carefully unpacked as a political affirmation of attachment theory. The social space needs to be explored as a "transitional space," both metaphorically and literally (Winnicott, 1971).

\section{Peter Pan and Neverland}

In Deleuze and Guattari's "a thousand plateaus," they discuss the Dogon tribe and the Dogon egg as a depiction 
of the cosmos. This egg is of great relevance to the Dogon people and their culture. It is a significant place and space in which alternative modes of being and becoming can be made possible. In this sense it can be a useful way to consider Neverland. This similitude is one of connection to the universe, nature and life forces. Neverland can be viewed as a small plot of land, a Dogon tribe, a clever association of temporality (never) and spatiality (land), suggesting it does not exist, yet has a materiality. It therefore constitutes a perfect background for both a fairy tale and an exploration of the potential deterritorialization of child development. The Dogon is used philosophically by Deleuze and Guattari to highlight the limitations Western society has over the control of inner and outer worlds (Deleuze \& Guattari, 1988/2013). Therefore, the value of the Dogon myth is that it offers an alternative perspective: that is, thinking of the Lost Boys as a potential Dogon tribe and war machine.

Peter Pan embodies a free spirit. He is also a child who is said to have run away from his parents, and this is presented as a liberating though occasionally complex and emotional state, because he finds himself yearning for familial love. Peter deterritorializes himself from his place in a family and presents the constant battles between territorialization (considering Neverland as a new territory, on which some order is being established, as Peter is the chief) and deterritorialization. In Greek mythology, the god Pan represents the natural state of human beings, in contrast to the shaping effects of child development. Thus, through his name only, Peter Pan opens up the nature (at once unwieldy, unruly, and biologically organized) versus nurture (portrayed as channelling and restricting) debate.

The transitional space is the Neverland within which Peter Pan dared to step. His stepping into that transitional space then becomes a wondrous journey into a fantastical (virtual) space of pure immanence, illustrating the flux and flow between the smooth and striated nature of childhood, and how childhood constitutes an emergence. We are not conflating idealism and immanence here, but by seeing the virtual (fantastical and abstract) and actual (reality) collide we can bring alternative thinking to our understanding of the complex vagaries of childhood. The development of Peter Pan's relations with multiple others and the material world encapsulate his social agency and agentic power. This parallels with the notion of hybrid childhoods, which Nick Lee and Johanna Motzaku describe as "unchartered space in which novel and unpredictable connections between forces and processes of many kinds can occur" (Lee \& Motzkau, 2011). Through intra-

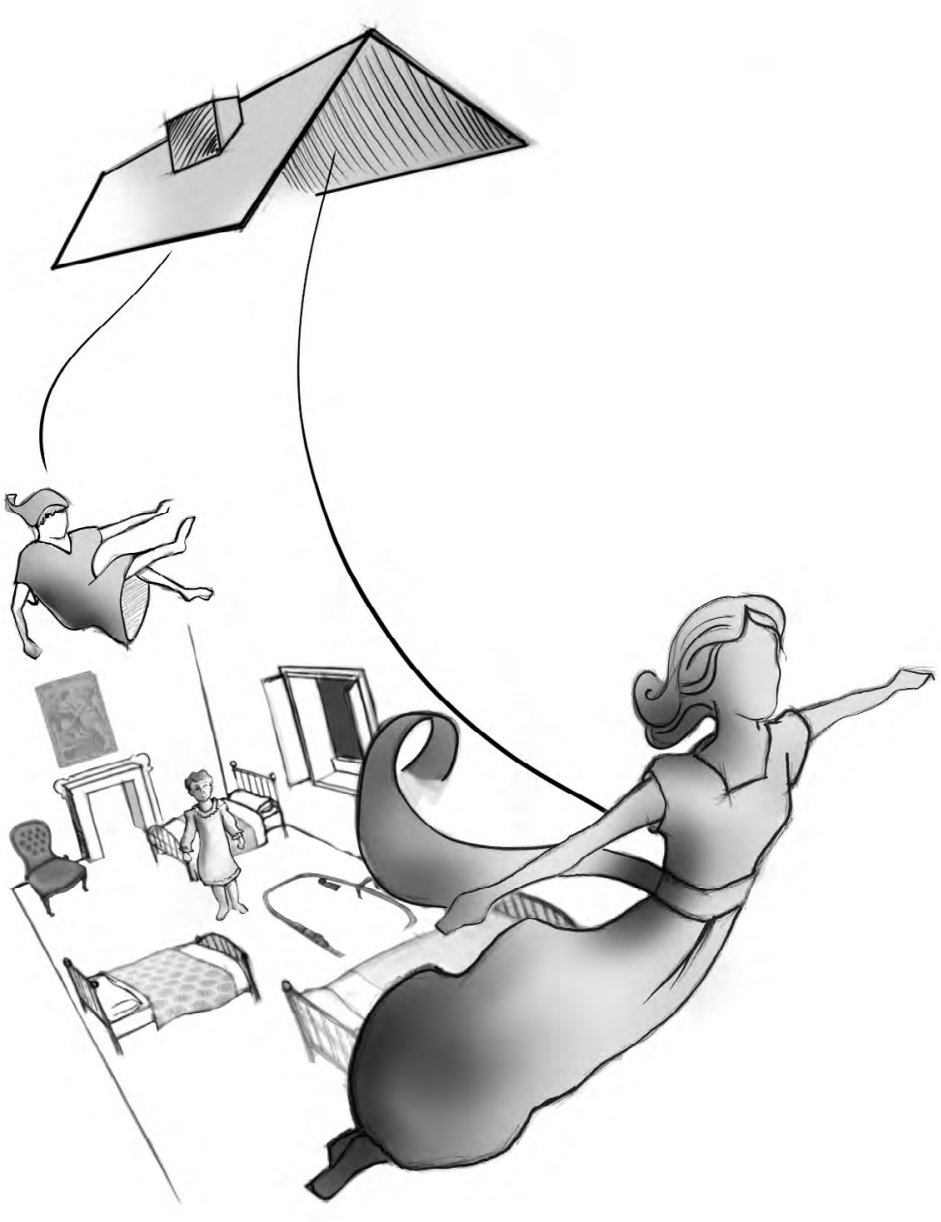

Figure 3. Nursery flying. action and entanglements, Karen Barad (2007) depicts a new materialism within which children can become agentic (Barad, 2007). These lines of flight and virtual events can be seen as agentic cuts, a departure from the centrality of attaching to one's lateral connections (see Figure 3). 
Poststructuralism also conjures up new possibilities, and so we have attempted to assimilate poststructuralist ideas as a fairy-tale narrative by way of exporting seemingly innocuous concepts into the world of Peter Pan and Neverland. In doing so, we hope to make connections and convey meaning in texts otherwise left obscure, abstract, unknown, and imaginary.

\section{An essentialist visual portraiture}

By merging text and images we immediately reveal an experience that is quite literally neither flat nor fixed. This merging allows for not only the creative and visual materialization of affect, but also an understanding of the spatiocomplexity of attachment theory, which cannot be fully realized through text alone. Through the depiction of movement and the rhythmic event, new possibilities emerge and envelop a process of change and transformation. Nick Sousanis (2015), for example, exported images and innovative graphic shape-shifting examples in his groundbreaking Unflattening project, dismantling the flatness of sight and its one-dimensional state to open up the multiplicity and potentiality of space, time, and experience. His emphasis is on the moving dynamic and mode of sketching between artistic embodiment and the production of an image. This resonates well with Paul Klee's idea of "taking a line for a walk" and making the abstract appear multidimensional and inter-corporeal (Klee, 1964). As Sousanis so succinctly comments, "By orchestrating the relationship between elements and the space they inhabit, we can trigger correspondence with experience both seen and felt" (2015).

Andrew Causey adds further weight to the discussion in his account of "being drawn to see" what lies below the surface and beyond the realm of everyday perception (Causey, 2017). Through drawing and sketching events and experiences, Causey alerts us to the embodied-corporeal nature of process: How the very act of sketching or drawing enlivens visual-materiality and knowledge through its unique kinaesthetic properties and thus is not able to be reprehended by any other means. Vicki Cope, Bronwyn Jones, and Joyce Hendricks also promote the use of portraiture as an important vehicle for depicting events as personal stories and narratives (Cope et al., 2015). A drawer, sketcher, or portraitist listens for the story and is literally engaged in and central to its creation (Lawrence-Lightfoot, 2005). As Eva Broxenbaum, Candace Jones, Renate Meyer, and Silviya Svejenova posit, a visual-material "turn" opens up exciting opportunities, enabling scholars to reach wider audiences, thus becoming more accessible and engaging (Broxenbaum et al., 2018). In addition, the visual-material turn ensures scholars do not ignore visuals or verbal text and their entanglement, therefore minimizing the risk of their missing major aspects of what is going on (Höllerer, Jancsary, \& Grafström, 2018). Thus, our aim here is to engage you, the reader, in our alternative story and narrative, providing a new backdrop, a new canvas on which to see attachment theory in all its multiplicity.

\section{Multiple attachments}

Duschinsky, Greco, and Solomon purport in their critique of attachment theory that the political discourse in Britain since 2009 has been enmeshed with the territorialization of sovereign power through attachment theory being subsidiary to notions of social construct to control social norms (Duschinsky et al., 2015b). They also recognize Deleuze and Guattari as powerful allies in reflecting on the movement of human individuation (the separation of self from states of power), autonomy, and relatedness (Duschinsky et al., 2015a). Thus, attachment theory has the effect of a striation, a constriction of alternative connections (Deleuze \& Guattari, 1988/2013). For feminists and sociologists, the standard practice of rendering mothers solely responsible for "policing" infants highlights the exclusion of fathers as a serious concern in discourses of the "family" around gender (Burman, 2016; Butler, 2004). Cross-cultural differences also challenge the claim of the universality of attachment theory, and studies have shown variations on this theory that challenge the reduction of behaviours into categorizations 
and coding, meaning they are not culturally sensitive or sacrosanct (Music, 2011). While research continues to strengthen Bowlby's contribution to the field of developmental psychology, it is somewhat intriguing that studies in general tend to use small sample sizes, with non-human (canine) subjects, or dolls, without corresponding conceptual expansion (George \& Solomon, 2016; Schoberl et al., 2016).

Juliet Mitchell (2003) and Judy Dunn (1983) both discuss the significance of sibling relationships in their evocative writings. Mitchell refers to Bowlby's "misleading matricentrism" and calls for acknowledgment of multiple kin (Mitchell, 2003). What is also stimulating about Mitchell's exposition is the way in which she describes "vertical" and "lateral" dimensions to relationships, politely deriding Bowlby for verticalization and his need to focus on the mother as "care-giving machine" (see Figure 4) when lateralization occurs early in infancy between siblings and in social play with peers. Kraftl (2013) also points out that expressions of love and empathy are not unique to the parent-infant dyadic relationship but are also found between children and adults who are not related.

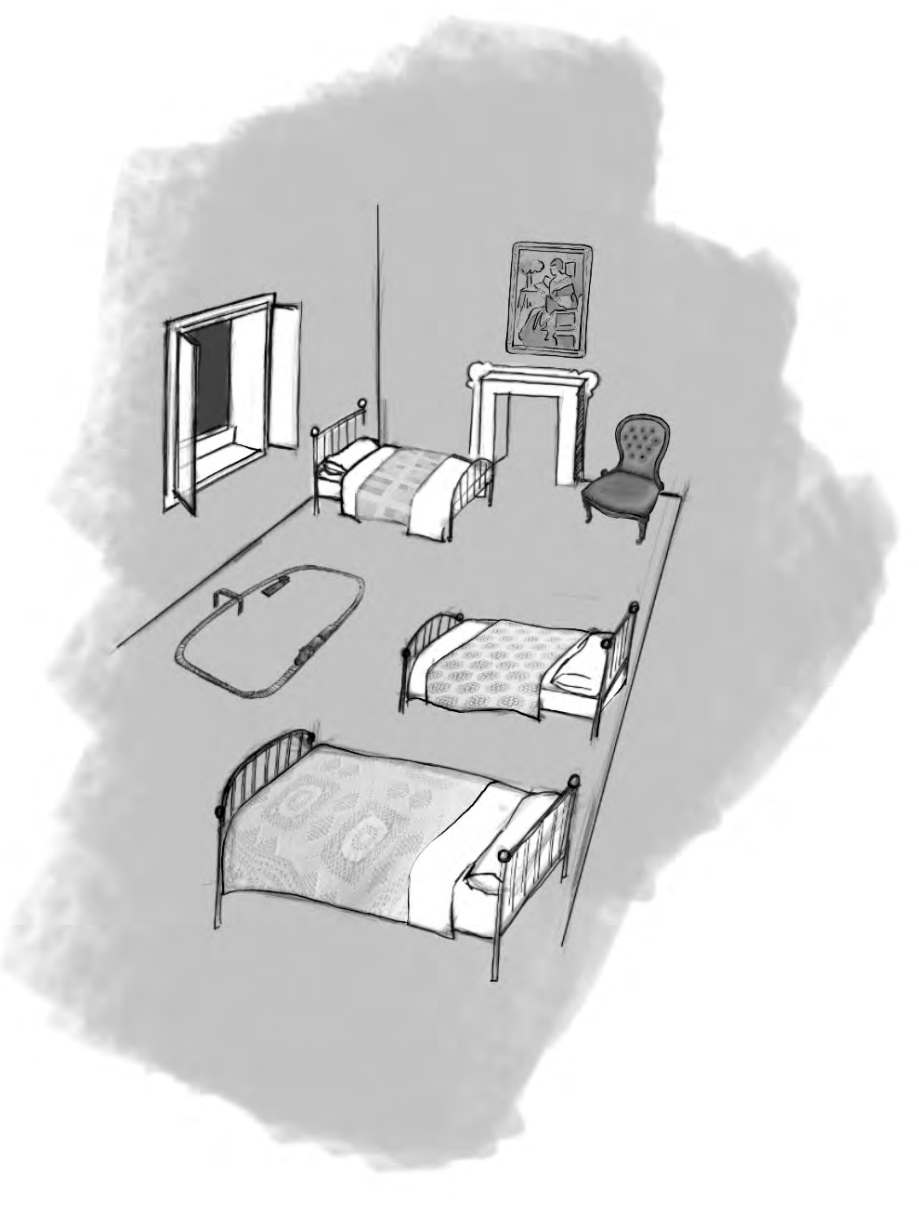

Figure 4. Nursery: Inside the care-giving machinevertical attachment (bonds).

Such relationships could be between the child and their peers, teachers, grandparents, aunts, uncles, and even pets. This again has a spatial and temporal element that can be valuable when measured in interactions, but has so far eluded in-depth analysis through the lens of attachment theory.

However, the writings of Stern on his idea of the reciprocal "dance" inject renewed optimism about providing affective forms of vitalityas a keyingredient of interactions (Stern, 2010). Furthermore, the idea of "allo-parenting" is usefully explored by Graham Music, who attributes the need to appreciate crosscultural differences in respect to attachment theory and the raising of children by more than one primary carer (Music, 2011). In addition, Cynthia Willett (2012) compels us to stretch the ethical boundaries of our approaches to understand the ecological components of relationships. Through the turn to research on "affect attunement," we open up the reconfiguration of relationships to "non-egoistic, preconscious immersion in the rhythms and tones of life" (Willett, 1995, p. 24). This appealing prospect will be taken up later.

Despite these challenging and insightful debates, the very idea of multiple attachments remains undertheorized within the literature. Attachment theorists, while conceding the importance of multiple attachments, have been somewhat remiss in exploring how children integrate multiple attachments into their internal working models of relationships. Patricia Crittenden's dynamic maturational model of attachment has at least in part exemplified the idea that there is progression and adaption across the life span, and it seems to call out for an expansion of the true fluidity in human development (Crittenden, 2008/2016) (see Figure 5). 


\section{Wendy and her siblings: Finding space to become}

If we return to the central tenet of how childhood is viewed through an adult construct, perhaps the most enduring issue is one that concerns ideas of "being" and "becoming." Agency is also a key consideration-and a widely contested area both theoretically and philosophically (James, 2001; Prout, 2005). As Barad suggests, agency is not an attribute an individual has but is a dynamic relational process (entanglements) through intraactions. In viewing agency as such, we can then become open to the possibility of "worldly re-configurations" (Barad, 2007). This entails thinking about both human and non-human relationships beyond the traditional dyad (parent-child) or triad (mother-father-child).

The story of Peter Pan embraces the parallel story of Wendy and her siblings embarking on a journey to Neverland and provides a delightful way in which to export some of Mitchell's and Dunn's ideas regarding the relevance of sibling relationships. Wendy is a middle-class Edwardian schoolgirl who shares a room with her two younger brothers. While she is portrayed as having positive attachment to both her parents, she also shares close ties to her siblings as

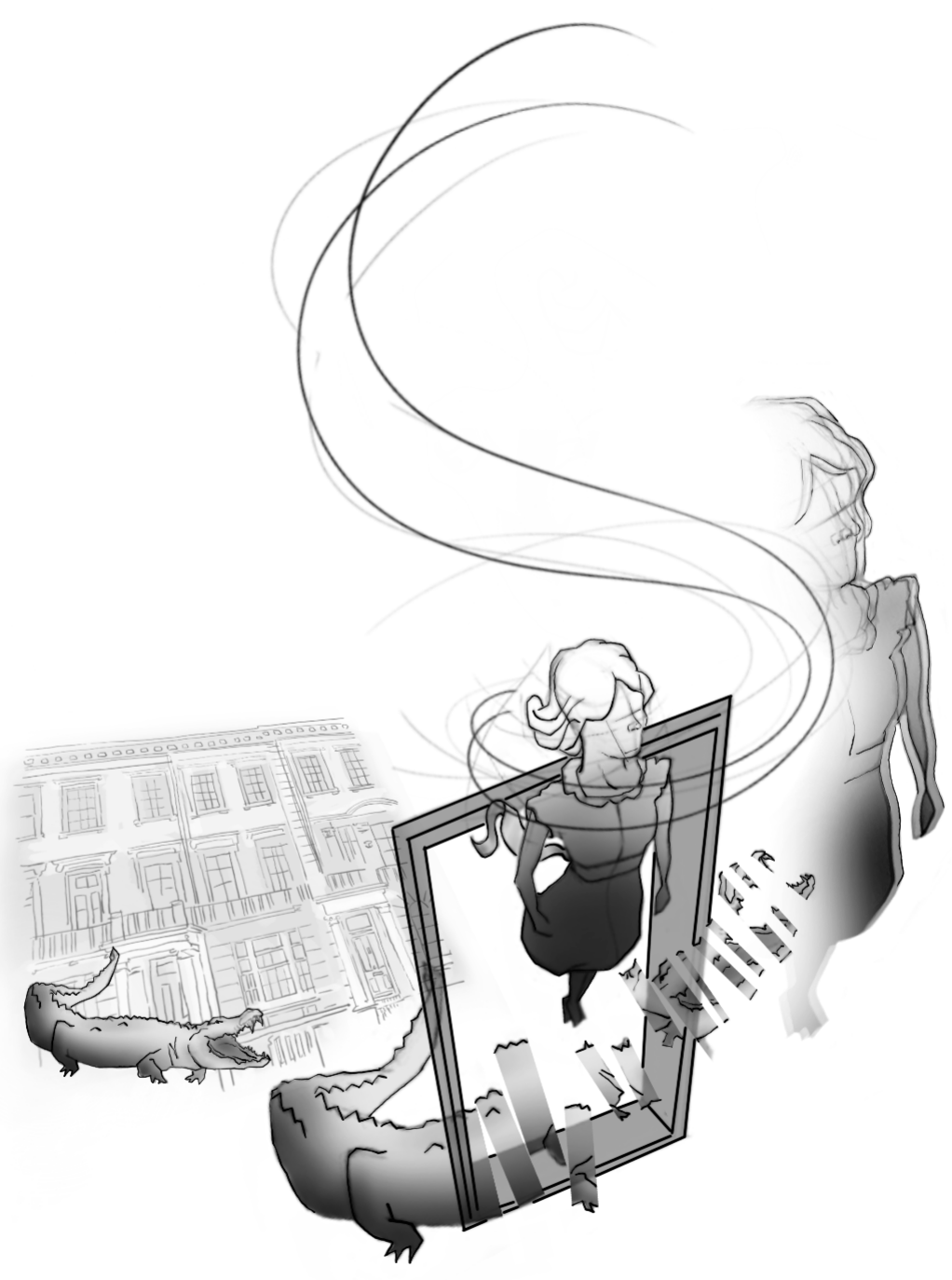

Figure 5. Wendy through the window: De-territorialization in flightescaping the un/pleasantries of adulthood. well as to Nana, the family dog. Similar to Peter Pan, she is on the brink of adulthood and wishes to escape its un/ pleasantries (see Figure 5). In an intriguing example of Wendy's "becoming-playful," she enters into entangled encounters with Peter Pan and the Lost Boys as a pseudo-mother figure. This othering of Wendy is a narrative that aligns with attachment theory's early roots. Even Nana is othered and anthropomorphized, becoming a nurse and caregiver, making beds in the nursery, and carrying out various domestic chores (see Figure 6).

Wendy enjoys telling stories and fantasizing. Meeting Peter Pan affords her the opportunity to try to avoid growing up, as she flies with her brothers to the imaginary land of Neverland, where they may cease to age (Boulton, 2006). Somewhat ironically, however, this experience seems to bring out Wendy's more adult side, because she becomes a de facto mother for the Lost Boys.

The lack of girls in the film, and the limited agentic possibilities for those who are featured, cries out for a feminist perspective to plaster over the cracks in perceived and anticipated notions of childhood development (Shipley, 2012). We can ponder whether J.M. Barrie would "other" Wendy with a more contemporary and acceptable 


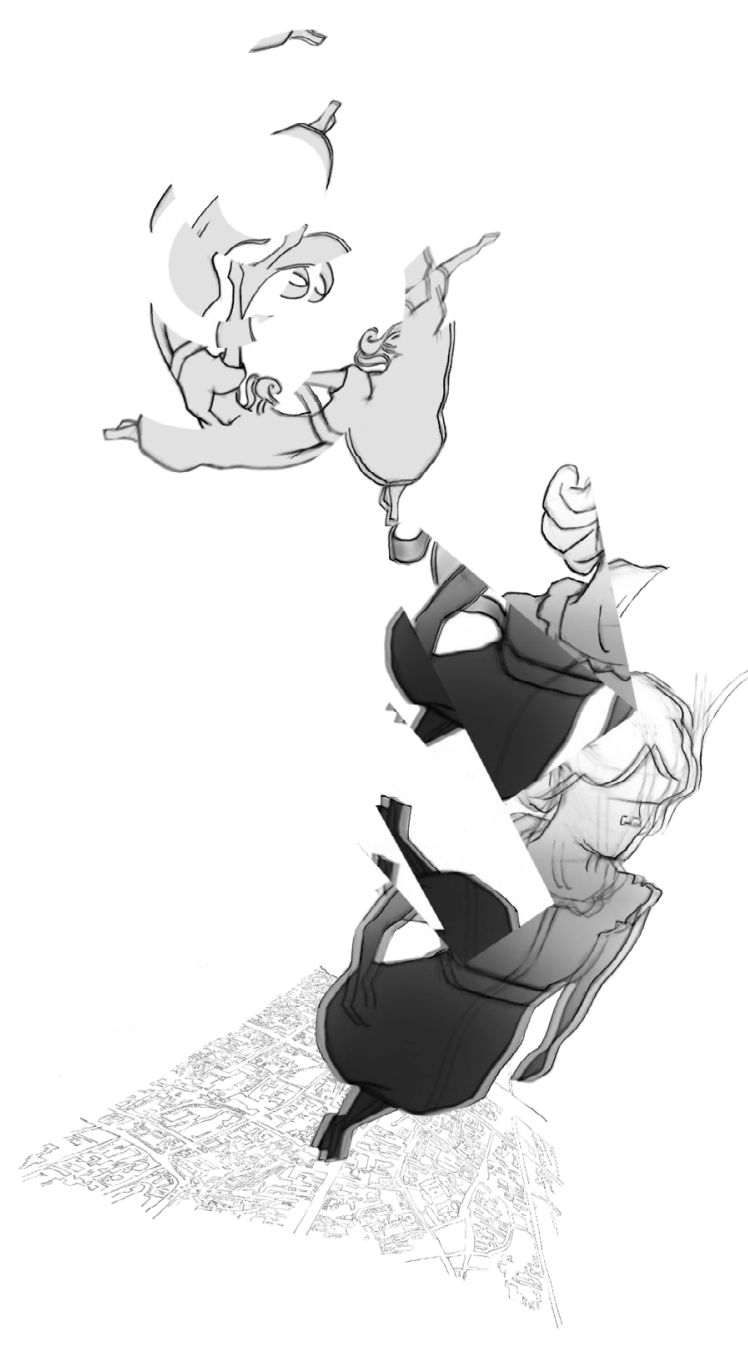

Figure 6. Wendy remixed and "othered." characterization if he were to rewrite the story today. Inevitably, Wendy would have to flee from the parallel attachment relationships that "mother" and "other" her character and pursue new lines of flight to a current day transitional space, which enables a becoming-adventurous state alongside Peter Pan. Ironically, Peter Pan unwittingly hastens Wendy's passage to adulthood, and once Tinkerbell is added to the mix, an oedipal triangle is emergent, potent, and problematic. One might see Neverland as a place and space with the dual and ambivalent purposes of freedom and nurturance (Boulton, 2006). Deleuze and Guattari (1988/2013) would reject such (psycho) dynamics and ensure the continuous need for deterritorialization to prevail.

Children's spaces and their relevance to childhood and developmental pathways is undertheorized within the literature, with Peter Moss and Pat Petrie inviting a new kind of practice and policy evaluation (Moss \& Petrie, 2002). We wish to contribute to this evaluation and offer new ways in which to consider children's spatiality and agency. By inviting professionals and scholars to explore our merged text and image, new perspectives can surface, appear, and materialize.

Neverland presents a space in which children can explore and become "other." As Deleuze asserts in his essay "What Children Say," children never stop drawing maps and talking about them (Deleuze, 1998). By this, we can infer that he is referencing how children explore all the potentialities and trajectories open to them, beyond the coordinates and limitations of mother and father (see Figure 7).

This is where the lines of similarity intriguingly cross and connect between Deleuze and Barrie. They share a mutual embellishment for the creativity of childhood (see Figure 8). On mapping, Barrie writes:

Your own map can be intensely interesting ... there are zig zag lines on it, just like your temperature on a card, and these are probably roads in the island, for the Neverland is always more or less an island, with astonishing splashes of colour here and there (1911/2018, p. 3).

Winnicott provided examples of how attunement can be thought about differently through his ideas of symbiosis and individuation and his extension of Bowlby's ideas around attachment theory, which can be found in his conceptions of juvenile delinquency (Winnicott, 1975/2014). Within the context of Winnicott's different (and pragmatic) approach to attunement, Pan can be seen as a runaway boy searching for an authority figure (perhaps Hook, his nemesis), in conflict with the flow and flux of reterritorialization, becoming liberated, becoming grown up. Such "anti-social" behaviours demonstrate a testing of loyalty (in the authority figure) and a desire for unconditional love. This is the paradox of Pan. As his fantasy world expands into all sorts of entanglements and relations (lateral and vertical), he is reworking, and indeed working through, his fears of abandonment, back and 
forth between the strata of deterritorialization and reterritorialization. Here, the true sense of being "rhizomatic" in Deleuzian terms is illuminated as Pan rather literally takes "lines of flight" to a plane of "immanence" and "pure bliss." It is somewhat ironic that Winnicott's playful theories earned him the nickname Peter Pan. The similarities are intriguing. Winnicott's "rescuing" of boys and taking them into his home to be cared for by his social worker wife, Clare, resonates with Pan's "nurturance" of the Lost Boys and his enlisting of Wendy as mother figure to help.

Winnicott (1975/2014) and Bowlby (1979) both developed their ideas in postwar Britain, when stay-at-home mothers-the norm for mothers at the time, of course-were encouraged to ensure their children developed secure attachment relationships. Prior to this sociopolitical climate, women were encouraged to take up jobs while

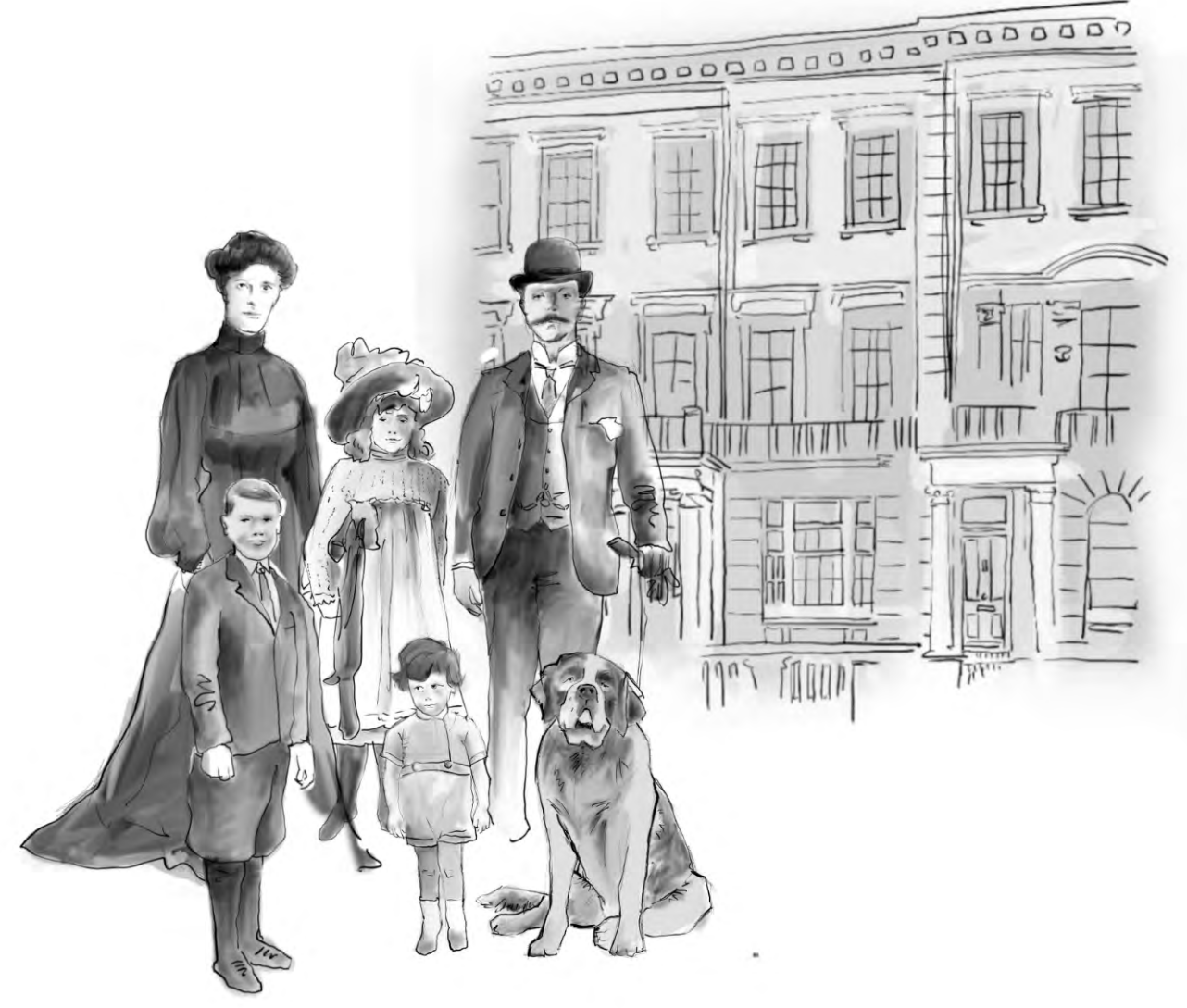

Figure 7. The Darling family. men went to war, disrupting the erstwhile equilibrium. The sovereign politicization of the ideas of attachment theory sparked the blaming of single mothers for the upsurge in "delinquency." Feminist arguments against the positioning of mothers as scapegoats for the wayward behaviour of children became central to attachment theories' apparent shift in paradigm. Lauren Berlant's lexicon of "cruel optimism" (Berlant, 2011) and Winnicott's notion of the "capacity to be alone" (Winnicott, 1958) further challenge the constraints and striations that might be imposed by the politicization and sovereign power of attachment theory. Thus, Berlant, by applying her refiguration lens to attachment theory, highlights seeing the care-giving system and attachment figure as an obstacle (sovereign schema) to a child's flourishing and development through the reduction of the needs of the child to meet the demands of the "attachment system" (Berlant, 2011). This orientates us to a social theory of affect and "affectability" and a site that provides fidelity to the texture of affect. Deborah Lupton also stresses the importance of affective dimensions in relational encounters and how caregiving seems to contain the regulation of bodies (infants) with such control and surveillance that it impedes potential infant and child wellbeing (Lupton, 2013). Similarly, Winnicott has discussed the idea and positive aspects of "sophisticated aloneness" as being a phenomenon that requires further examination, given the current dearth of discourse about it (Winnicott, 1958). Such a paradox completely upends current thinking, making a strong argument to explore the "fixed" ontology of relationships (see Figure 9) further with Berlant's optimism, which refigures attachment theory. This is illustrated by Duschinsky, Greco, and Solomon, 
who assert: "The child is more than the product of their attachment, and their attachments offer a surprising excess of labile affect which disturb subjectivity and open up possibilities for becoming" (Duschinsky et al., 2015b, p. 234).

\section{Finding a symbiotic sea-soup (smooth space) in vectors of entanglements}

Time is reductive. It is mathematized to the tune of units, measures, clocks. It is the enemy of Peter Pan. A crocodile embodies the tick-tock of time-an aggressive amphibian lurking in the background snapping at the heels of childhood. Yet there is something strangely endearing about the crocodile's tick-tocks (see Figure 8).

He also lurks within water-diverse, vast, smooth strata where freedom of movement is guaranteed. An enticing safe space (secure base) to dwell. A symbiotic sea-soup. An enabling of scholars and professionals to swim in our sea-soup to challenge boundaries and provoke alternative thinking. We have playfully taken Crocodile's ambiguous character and virtually catapulted him into the nursery (see Figure 3) unbounded, changing his entire persona and taming time, becoming transformed. This is our depiction of how the synergy of image and text can change perception.

In the actual spaces of Neverland, Crocodile also has a taste for Hook, which Peter Pan encouraged by throwing him Hook's hand to devour. Hook symbolizes authority, a thorny inconvenience of childhood. A restricting rope, one that has to be cut to allow lines of flight. Peter Pan is the epitome of this cut-a vectorial (sign) of affects that Deleuze describes as having both agentive and "augmentive powers and diminutive servitudes" (Deleuze, 1998). This means that Peter Pan's free spirit creates entanglements with the human and non-human entities in the world around him (Neverland). Peter Pan's puissance engages the fairies (he plays his panpipes to summon them), his refrain, rhythm, and movements enacting forms of vitality and affect attunement (Stern, 2010). The spaces of childhood are thus augmented, in flow and flux, through a collective intensity and energy. A sonorous delight in deterritorialization. An expansion and contraction. An increase and decrease. Becoming nomad. As Deleuze shrewdly purports,

Vectorial signs in general, that is, affects, enter into variable associations as much as do affections: what is growth for one part of the body can be diminution for another part, what is servitude for one part is power to the other, and a rise can be followed by a fall. (1998, pp. 140-141)

In conceptualizing children as "vectors of entanglements" (Carlyle, 2018), we can reconfigure their relationships and interactions (human and non-human) as multiple entanglements that afford agentive power or confirmative rule. Peter Pan encounters both sorts inside Neverland. He enlists the Lost Boys, who become his war machine against adulthood. As Deleuze and Guattari assert, the "war machine" is "directed against the state apparatus" (Deleuze \& Guattari, 1988/2013). This war machine is embodied

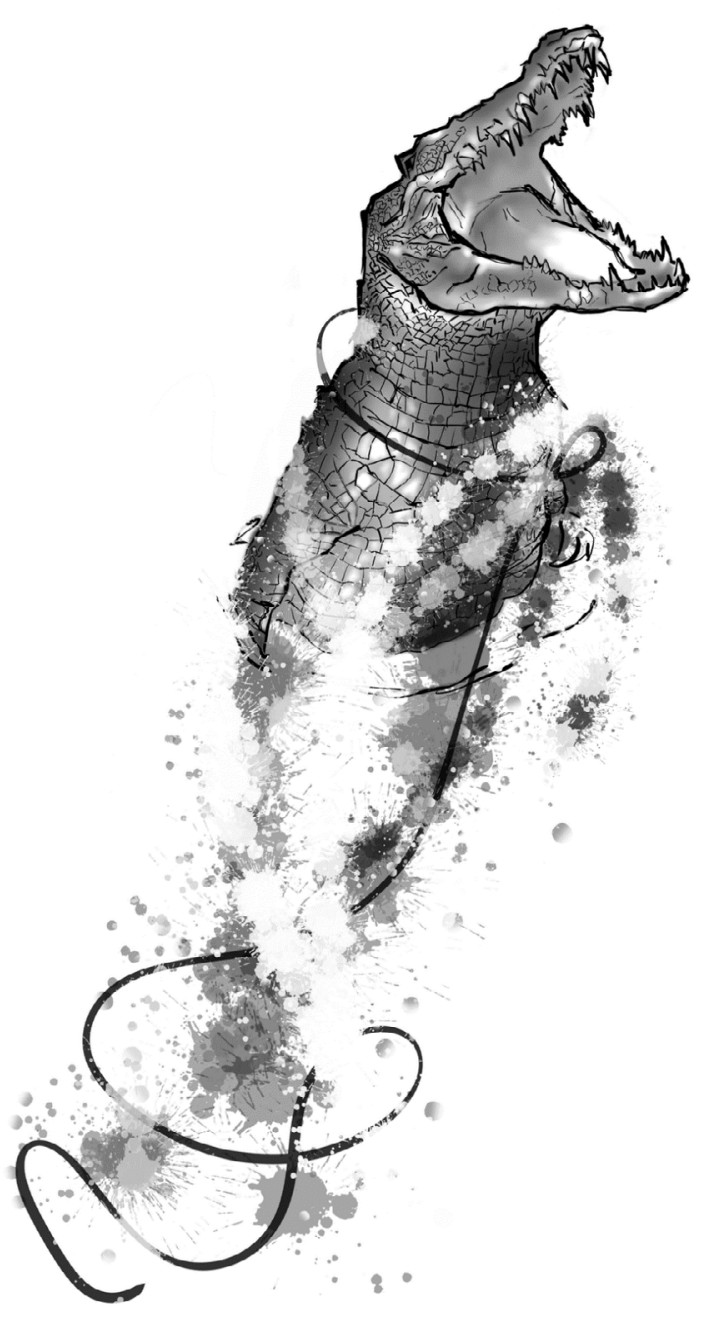

Figure 8. Crocodile snapping at the heels of childhood-tick-tock. 
and enacted through the ship the Jolly Roger (see Figure 9). As soon as Peter Pan suspects a part of his war machine is malfunctioning (e.g., a boy reaches puberty), he destroys and replaces it. His war machine also rages against Hook and his band of pirates. In uncanny parallels with Winnicott's (1975) notion of "hate in the transference," Peter Pan both despises and admires Hook-an ambivalence with which he truly tests Hook's authority and commitment, just as Winncott's fostered evacuee children did with him (running away from home). Peter Pan seeks to devour and destroy Hook to maintain his chief command in the benevolent joy of childhood and quest for smooth space. In parallel with Deleuze's ides of the cosmos, Peter Pan and the Lost Boys can be considered similar to a Dogon tribe: they resist order and organization, creating their own maps (Deleuze, 1998).

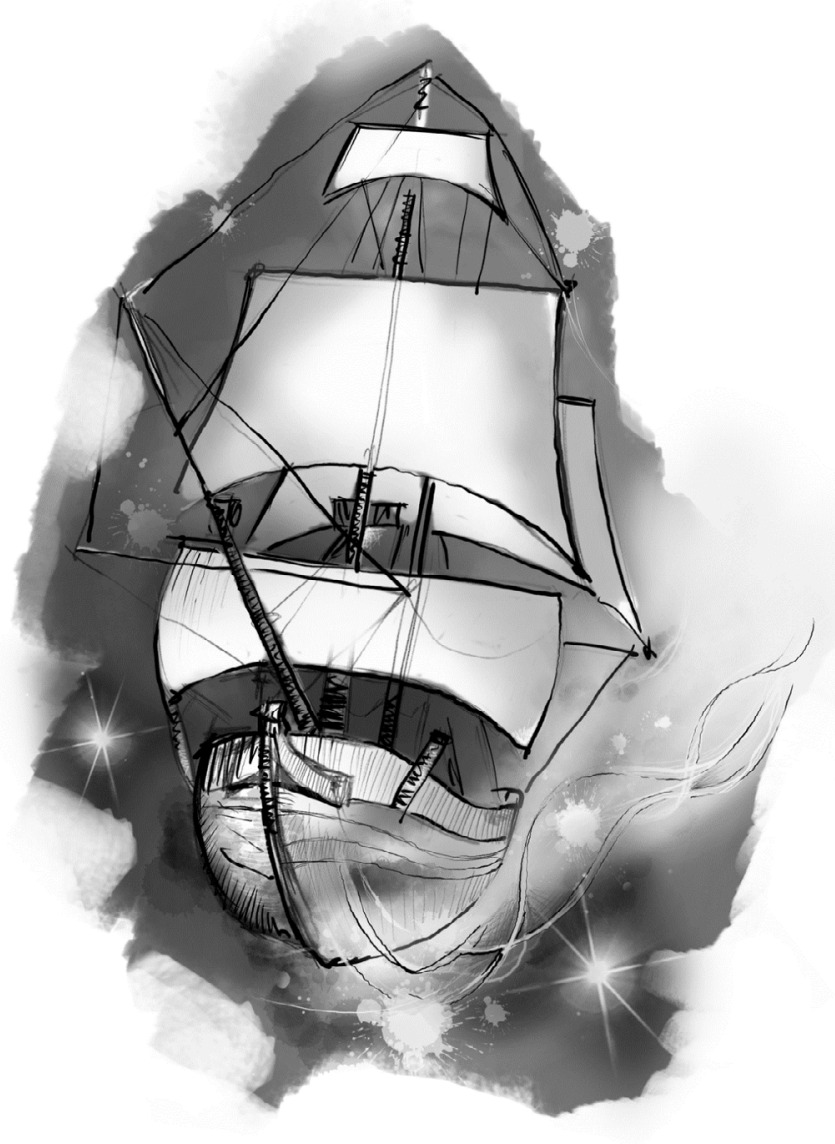

Figure 9. Jolly Roger: The Lost Boys as war machine.

\section{A Body without Organs (BwO)-always becoming}

In order to disrupt the fixed identity that attachment theory can often characterize, Deleuze and Guattari (1988/2013) consider the body without organs (BwO) to illuminate and deconstruct our notions of order, regulation, and control, thus extending as a plateau and place of immanence (a region of continuous flows of intensity that do not allow the interruption of external formation) as a way of becoming subjective and "wildly destratifying." This occurs by being adventurous in our sensations and perceptions. The $\mathrm{BwO}$ is born out of the rejection of psychoanalytical efforts to define and root subjectivities solely in the Freudian triad: mother-child-father. It is a surface characterized by flows of intensity, sensations, and feelings (see Figure 10). It is a practice that enables experimentation and recognizes that our unconscious is indefinitely rewritten through our experiences in the world, in a constant state of becoming.

In juxtaposition to attachment theory, Deleuze and Guattari (1988/2013) purport a need for the stratified, dominant, and hierarchized functions and forms of organizations of the body to be dismantled, deterritorialized, and set free. They state:

This is how it should be done: Lodge yourself on a stratum, experiment with the opportunities it offers, find an advantageous place on it, find potential movements of deterritorialization, possible lines of flight, experience them, produce flow conjunctions here and there, try out continuums of intensities segment by segment, have a small plot of new land at all times. It is through meticulous relation with the strata that one succeeds in line of flight, causing conjugated flows to pass and escape and bringing forth continuous intensities for a BwO. (1988/2013, p. 187)

Deleuze and Guattari oppose the idea that our unconscious is somehow at the core of our personality. Instead, they posit there is no distinction between the centre and the margins and there is a free-flow of relationships and influences, interweavings and cross-fertilizations that are being permitted by the $\mathrm{BwO}$. Children can therefore be 
conceptualized as BwOs, which are characterized by flows of intensity, sensations, and feelings. Attachment theory constitutes a striation of the $\mathrm{BwO}$ (see Figure 10).

Beyond dyadic and ethnocentric caregiving, Deleuze and Guattari thus offer a disruption of attachment theory (Deleuze \& Guattari, 1988/2013). This disruption can allow for reconceptualization of the child as a "vector of entanglements," and thus as a being with multiplicity and multiple "entanglements" as opposed to attachments alone (Carlyle, 2018). The attachment striation limits the extent to which children's subconscious is seen to bleed into and change the social context within which they live. In addition to this, as aforementioned, further consideration of the important relational dynamic can enlighten contemporary attachment theory and its notion of the spatial and temporal nature of interactions, wherein children's capacities are extended and enhanced by all kinds of material artefacts and non-human encounters (Aitken \& Herman, 1997; McCormack, 2002; Music, 2011).

The primacy of desire over power is significant for Deleuze in terms of the transformative potential of human becomings (Deleuze, 1998). Deleuze and Guattari (1988/2013) help extend boundaries of becoming by allowing the synthesis of spatial and temporal mapping to enhance our perspective on human development and potential. Indeed, Mitchell's vertical and lateral configurations fit well with such a paradigm, albeit by nature. Deleuze and Guattari (1987/2013) call for continuous deterritorialization. Such aspirations are subject to continual reterritorialization and stratification, but the agentic and temporal cuts can enable richer perceptual and sensorial experiences, far beyond the current realms of defining the essence of childhood.

Infants could thus be conceptualized as a BwO characterized by flows of intensity. Attachment theory presents a striation: It presents a degree of explanatory organization / categorization, which might limit the extent to which children can enter into a dialogue or exchange between their unconscious and the social context in which they live, thus possibly limiting their potential for development in ways that are different.

\section{The rhythms and tones of life}

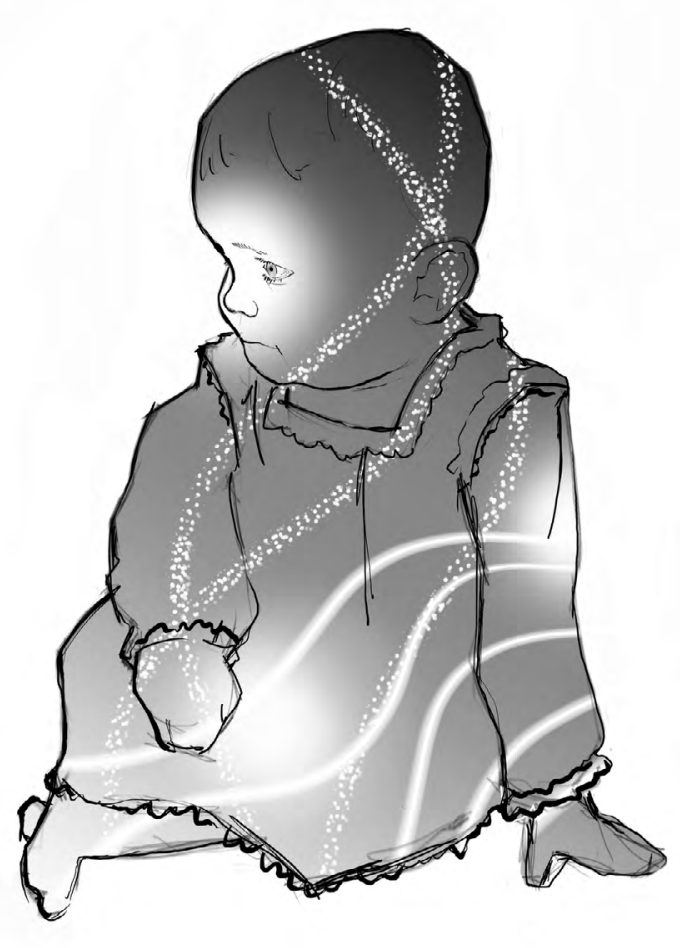

Figure 10. The Infant and a BwOs: Flows of intensity, sensations, and feelings.

A further useful way with which to deconstruct attachment theory is through consideration of the work of Eleni Ikoniadou and the turn against representation, bequeathed from Platonic and Cartesian privileging of language and intelligence (Ikoniadou, 2014). Thus, we can reconfigure more dynamic ways of knowing and appreciating of the body's movements and events. This welcome poststructuralist turn from language is a significant shift toward developing alternative pathways to the understanding of relationships in terms of bodies, space, and rhythm. In doing so, Ikoniadou aids exploration of the affective encounters that remain outside of cognition, a dimension of experience, which is "unthought." Katherine Hayles has taken up this trope, which highlights that affects are indeed significant, comprehensively so (Hayles, 2017). As well as bypassing cognition, affect has even escaped contemporary thinking on the finer nuances of relationships (Brennan, 2004). 
Derek McCormack and Erin Manning have respectively taken up the Deleuzian idea of "rhythms of the refrain" in a lively and captivating depiction of the significance of movement and intercorporality in relationships (McCormack, 2013; Manning, 2009). This exposition enables a shift from attachment theory in the sense that we can "become with" rather than just "become through" our relationships with others. It offers an agentic cut as opposed to an attachment tie. Thus, attachment theory should be viewed as culturally bound and as an assemblage of entanglements beyond the current didactic restrictions. Attachment theory needs to take account of the affects, intensities, and forces of the wider environment. As Stern highlights, other forms of vitality need accommodation in our understanding of child/human development (Stern, 2010).

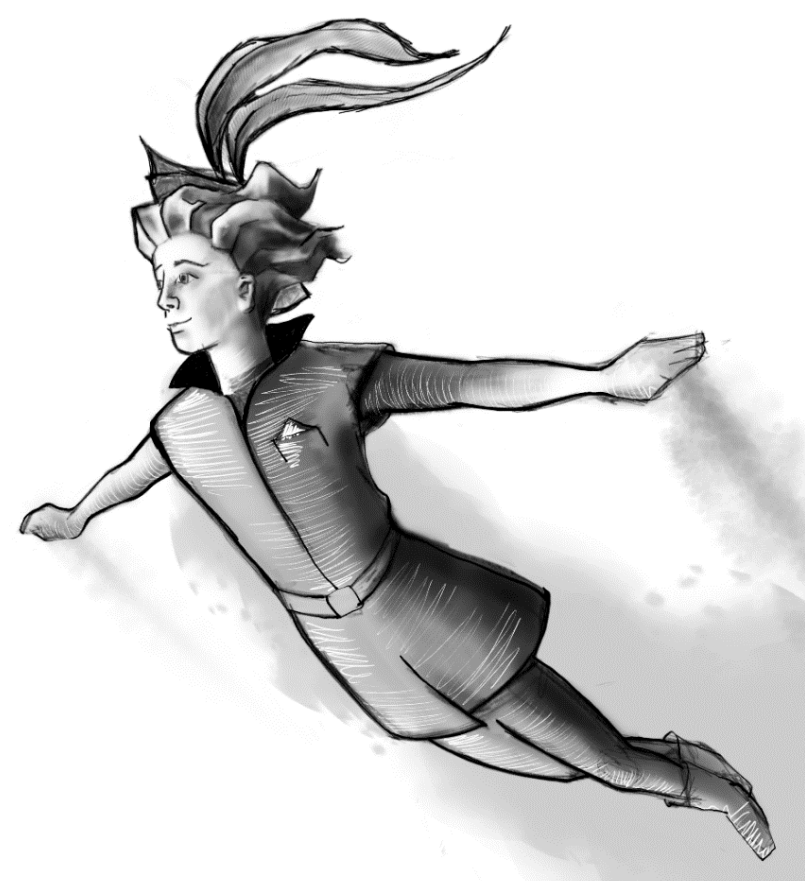

Figure 11. Peter Pan's "lines of flight."

With child mental health being highlighted as an area for future development (Children's Society, 2008; OECD, 2017), the genre of the fairy tale can remind us of the healing and provocative power of fostering creative, lively, and healthy relationships, relationships that take new lines of flight toward cartographic paths of growth and development.

\section{Discussion}

Peter Pan casts a rather lonely figure. In the end, he remains in Neverland with the Lost Boys, Tinkerbell, and the fairies. Wendy and her brothers return to the Darling household with renewed understanding of their parents and the concept of growing up. Perhaps the hidden message of the story is that time cannot be stopped, because transformation and becoming are constant. We can play with time: We can waste it, measure it, try to hasten it, and try to turn the clock back. Nevertheless, it is a given. We are always "becoming other," something more, and 
something else. We are not fixed entities with codified behavioural patterns. Repetition is not restriction. Time enables all kinds of relationships to unfold. Remaining the same implies we do not flourish or "augment."

In this article, we have offered further reflection on current debates as to how children create all kinds of entanglements to spur a deterritorialization of attachment as a key theory of child development. In presenting the intra-action (co-constitution and transformation) of image and text we hope to exemplify the power of metaphor and fairy tales in meaning making. Engaging with them in text and image creatively enables both an illustration of thought in process (line of flight) in and of itself, and a further, perhaps more creative and engaging critique of a well-established concept. As Denielle Elliott and Dara Culhane purport, the imaginative trope of the fairy tale can help us experiment (in research methods) with the fairy tale as a performance to facilitate a kinetic learning process about another's culture and way of life (Elliott \& Culhane, 2017). This process provides embodied understanding, not just descriptive and detached representations. Thus, spaces of inquiry are opened up to make visible the unknown. Therefore, through our article and visual-materialization, we animate our infinite entanglements in the world.

Deleuze invites us not to view children through the referential coordinates of parents but instead to consider the milieux they move through. We must connect with cartographic trajectories of child development, becoming dynamic. The twist for Peter Pan is that he actually remains tied and confined to the servitudes of time, rather than becoming master of them. He is far from being free and "in flight." If we resist time (and change), we get caught in a loop like Peter Pan and miss out on all kinds of possibilities, multiplicities, and becomings. Tick tock. Time flies when you are having fun, we hear him ruminate. 


\section{References}

Aitken, S. C., \& Herman, T. (1997). Gender, power and crib geography: Transitional spaces and potential places. Gender, Place and Culture, 4, 63-88. https://doi.org/10.1080/09663699725503

Anderson, B., \& Harrison, P. (2010). Taking-place: Non-representational theories and geography. Burlington, VT: Ashgate.

Barad, K. (2007). Meeting the universe halfway: Quantum physics and the entanglement of matter and meaning. Durham and London: Duke University Press.

Barrie, J. M. (1911/2018). Peter Pan. Reprint. Owen Smit (editor). Createspace Independent Publishing Platform, Great Britain.

Berlant, L. (2011). Cruel optimism. Durham: Duke University Press.

Bettelheim, B. (1975/1991). The use of enchantment: The meaning and importance of fairy tales. London, UK: Penguin Books.

Boulton, N. (2006). Peter Pan and the flight from reality: A tale of narcissism, nostalgia and narrative trespass. Psychodynamic Practice, 12(3). Retrieved from https://doi.org/10.1080/14753630600765709

Bowlby, J. (1979). The making and breaking of affectional bonds. London, UK: Routledge.

Brennan, T. (2004). The transmission of affect. Ithaca, NY.: Cornell University Press.

Broxenbaum, E., Jones, C., Meyer, R. E., \& Svejenova, S. (2018). Towards an articulation of the material and visual turn in organization studies. Organization Studies (Special Edition), 39(5-6), 597-616. http://doi.org/10.1177/0170840618772611

Burman, E. (2016). Deconstructing developmental psychology (Vol. 19). London: Taylor and Francis Ltd.

Butler, J. (2004). Undoing gender. Cambridge: Polity.

Carlyle, D. (2018). Re-energising the role of vitalism theory in child development, nature orientation and research. Contemporary Issues in Early Childhood, 19(3), 246-255. https://doi.org/10.1177/1463949117715942

Causey, A. (2017). Drawn to see: Drawing as an ethnographic method. Canada, New York, USA, Plymouth, UK: University of Toronto Press.

Children's Society. (2008). The good childhood inquiry: Health research evidence. London. Retrieved from https://www.childrenssociety.org. uk/what-we-do/good-childhood-report

Cope, V., Jones, B., \& Hendricks, J. (2015). Portraiture: A methodology through which success and positivity can be explored and reflected. Nurse Researcher, 22(3), 6-12. https://doi.org/10.7748/nr.22.3.6.e1311

Crittenden, P. (2008/2016). Raising parents. Oxon, New York: Routledge.

Deleuze, G. (1998). Gilles Deleuze: Essays critical and clinical (D. W. Smith \& M. A. Greco, Trans.). London, UK: Verso.

Deleuze, G., \& Guattari, F. (1988/2013). A thousand plateaus. London and New York: Bloomsbury Academic.

Dunn, J. (1983). Sibling relationships in early childhood. Society for Research in Child Development, 54(4), 787-811. https://doi. org/10.2307/1129886

Duschinsky, R., Greco, M., \& Solomon, J. (2015a). The politics of attachment: Lines of flight with Bowlby, Deleuze and Guattari. Theory, Culture \& Society., 32(7-8), 173-195. https:// doi.org/10.1177/0263276415605577

Duschinsky, R., Greco, M., \& Solomon, J. (2015b). Wait up!: Attachment and sovereign power. International Journal of Political Culture \& Society, 28, 223-242. https://doi.org/10.1007/s10767-014-9192-9

Elliott, D., \& Culhane, D. (2017). A different kind of ethnography: Imaginative practices and creative methodologies. UK, USA: University of Toronto Press. 
Fleer, M., \& Hammer, M. (2013). Emotions in imaginative situations: The valued place of fairytales for supporting emotion regulation. Mind, Culture and Activity, 20(3), 240-259. https://doi.org/10.1080/10749039.2013.781652

George, C., \& Solomon, J. (2016). The attachment doll play assessment: Predictive validity with concurrent mother-child interaction and maternal caregiving representations. Frontiers in Psychology, 7(Article 1595), 1-12. https://doi.org/10.3389/fpsyg.2016.01594

Hayles, N. K. (2017). Unthought. The power of the cognitive nonconcious. Chicago and London: University of Chicago Press.

Höllerer, M. A., Jancsary, D., \& Grafström, M. (2018). “A picure is worth a thousand words": Multimodal sensemaking of the global financial crisis. Organization Studies (Special Edition), 39(5-6), 617-644. https://doi.org/10.1177/0170840618765019

Ikoniadou, E. (2014). The rythmic event, art, media and the sonic. Cambridge, Massachusettes, London, England: MIT Press.

James, A., Jenks, C., \& Prout, A. (2001). Theorizing childhood. Cambridge: Polity Press.

Klee, P. (1961). Paul Klee notebooks: The thinking eye. Vol 1. (R. Manheim. Trans.). London Lund Humphries. Retrieved from https:// archive.org/stream/PaulKleeNotebooksVol1TheThinkingEye/Paul_Klee_Notebooks_Vol_1_The_Thinking_Eye_djvu.txt

Klee, P. (1964). The diaries of Paul Klee. California: University of California Press.

Kraftl, P. (2013). Beyond “voice, beyond agency”, beyong politics? Hybrid childhoods and some critical reflections on children's emotional geographies. Educaation, Space \& Society., 9, 12-23. https://doi.org/10.1016/j.emospa.2013.01.004

Lawrence- Lightfoot, S. (2005). Reflections on portraiture: A dialogue between art and science. Qualitative Inquiry, 11(1), 3-15. https:// doi.org/10.1177/1077800404270955

Lee, N., \& Motzkau, J. (2011). Navigating the biopolitics of childhood. Childhood, 18, 7-19. https://doi.org/10.1177/0907568210371526

Lhussier, M. (2009). Quality of life: Nomadological insights. A nomadic exploration of quality of life in long-term conditions. Berlin, Germany: VDM Publishing House.

Lupton, D. (2013). Infants and objects. Presentation at the Relational Consumption: Beyond Individuals and Choices Workshop, Monash University, Melbourne August 16, 2013.

Manning, E. (2009). What if it didn't all begin and end with containment? Toward a leaky sense of self. Body and Society, 15(3), 33-45. https://doi.org/10.1177/1357034X09337785

McCormack, D. P. (2002). A paper with an interest in rhythm. Geoforum, 33, 469-485. https://doi.org/10.1016/S0016-7185(02)00031-3

McCormack, D. P. (2013). Refrains for moving bodies: Experience and experiment in affective spaces. Durham and London: Duke University Press.

Mitchell, J. (2003). Siblings. Oxford, England. Blackwell Publishing.

Moss, P., \& Petrie, P. (2002). From children's services to children's spaces. London and New York: Routledge Falmer.

Music, G. (2011). Nurturing natures. East Sussex, New York: Psychology Press.

OECD. (2017). PISA 2015 results (Volume III): Students' well-being. Retrieved from https://doi.org/10.1787/9789264273856-en

Prout, A. (2005). The future of childhood. Abingdon, Oxon: Routledge Falmer.

Rehn, T., McGowan, R. T. S., \& Keeling, L. J. (2013). Evaluating the strange situation procedure (SSP) to assess the bond between dogs and humans. PLOS One, 8(2), 1-10. https://doi.org/10.1371/journal.pone.0056938

Schoberl, I., Beetz, A., Solomon, J., Wedl, M., Gee, N., \& Kotrscha, l. K. (2016). Social factors influencing cortisol modulation in dogs during a strange situation procedure. Journal of Veterinary Behavior, 11, 77-85. https://doi.org/10.1016/j.jveb.2015.09.007

Shipley, H. E. (2012). Fairies, mermaids, mothers and princesses: Sexual difference and gender roles in Peter Pan. Studies in Gender \& Sexuality, 13(2). https://doi.org/10.1080/15240657.2012.682946 
Sousanis, N. (2015). Unflattening. Cambridge, Massachusettes, London, England: Harvard Press.

Stern, D. N. (2010). Forms of vitality. New York, USA: Oxford University Press.

Tesar, M. (2016). Timing childhoods: An alternative reading of children's development through philosophy of time, temporality, place and space. Contemporary Issues in Early Childhood, 17(4), 399-408. https://doi.org/10.1177/1463949116677924

Walker, S. (2010). Young people's mental health; the spiritual power of fairy stories, myths and legends. Mental Health, Religion and Culture, 13(1), 81-92. https://doi.org/10.1080/13674670903196721

Warner, M. (1995). From the beast to the blonde. On fairy tales and their tellers. London: Vintage.

Whatmore, S. (1997). Dissecting the autonomous self: Hybrid cartographies for relational ethics. Environment and Planning D: Society and Space, 15, 37-53. https://doi.org/10.1068/d150037

Willett, C. (1995). Maternal ethics and other slave moralities. New York.: Routledge.

Willett, C. (2012). Affect attunement in the caregiver-infant relationship across species: Expanding the ethical scope of Eros. PhiloSOPHIA, 2(2), 111-130. https://muse.jhu.edu/article/500109/pdf

Winnicott, D. W. (1958). The capacity to be alone. International Journal of Psychoanalysis, 39(4), 416-420. Retrieved from https://pdfs. semanticscholar.org/b491/33a8dcc46979911d506b75ca2407d787b74f.pdf

Winnicott, D. W. (1964). The child, the family, and the outside world. Middlesex, England: Pelican Books.

Winnicott, D. W. (1971). Playing and reality. New York: Basic Books.

Winnicott, D. W. (1975/2014). Through paediatrics to psychoanalysis: Collected papers (Karnac Classics). Abingdon, Oxon.: Routledge. 